\title{
XII Multifrequency Behaviour of High Energy Cosmic Sources Concluding Remarks
}

\author{
René Hudec ${ }^{1,2 * \dagger}$ \\ ${ }^{1}$ Czech Technical University in Prague, Faculty of Electrical Engineering, \\ Technická 2, 16000 Prague, Czech Republic \\ ${ }^{2}$ Engelhardt Astronomical observatory, Kazan Federal University, Kremlyovskaya street 18, \\ 420008 Kazan, Russia \\ hudecren@fel.cvut.cz
}

This paper contains the printed version of the concluding remarks I gave at the Conference XII Multifrequency Behaviour of High Energy Cosmic Sources Workshop, 12-17 June, 2017 in Palermo, Italy.

\footnotetext{
* Speaker.

${ }^{\dagger}$ This paper and author participation in the conference was supported by the grant GA CR 13-33324S. Photo courtesy in this talk: René Hudec and Rosa Poggiani. 


\section{Introduction}

The idea of international XII Multifrequency Behaviour of High Energy Cosmic Sources conference was to bring together researchers who are involved in various topics at the forefront of multifrequency astrophysics. The workshop discussed the most recent experimental and theoretical results in order to advance our understanding of various astrophysical objects based on multispectral approach.

In my opinion, the goals of the conference were achieved by a synergy between data from ground-based and space-based experiments, as well as results from theoretical developments. This work at the forefront of multifrequency science is very likely to result in scientific papers of significant import.

It is very obvious that the main purpose of the conference, which was to discuss in a unique and collaborative setting a broad range of topics in modern multifrequency and multispectral astrophysics, has been accomplished. It is evident that the scope of the conference has provided a suitable framework for each participant who (while obviously not involved in all the topics discussed), was be able to acquire a general view of the main experimental and theoretical results currently obtained.

Such an up-to-date view of the current multifrequency research on various astrophysical sources, as presented by conference speakers and participants, can help guide future research projects by the participants, and surely will encourage collaborative efforts across various topical areas of multispectral research.

\section{A very few subjective comments.}

There were nice reviews presented at the conference by various key speakers, covering both theory as well as experiment. Over last years there was great progress both in theory as well as observation/experiment as illustrated by many speakers. New detailed observations and simulations on numerous high-energy (HE) objects were presented. Nice results were presented from ASTRO$\mathrm{H}$ satellite, and we are very sorry that the mission failed after just one month in orbit. Few talks presented non-traditional and some even controversial ideas resulting in lively but still friendly discussion.

Common conclusion of many speakers was: more data, better statistics are needed, with focus on HE and even VHE/UHECR emissions, There is need for better monitoring, multi-lambda, observations. Robotic Telescopes and novel space experiments (eg LOBSTER) may help significantly, New view of old huge databases (machine learning) was also addressed, along with many other topics. This time, to make a review is extremely difficult as the topic covered was very very wide

There vere also very hot news presented during the conference. The highlight was the Chinese large (2,5 tons) $\mathrm{X}$ ray astronomy satellite launched during the workshop, with remote talk on this topic. And Czech minisatelite VZLUSAT1 will go to the space just after the conference on June 28,2017 , the satellite is just $2 \mathrm{~kg}$ only but with very new advanced technology, namely with the $1 \mathrm{st}$ Lobster Eye X-ray Telescope in space (Hudec et al., 2007, Urban et al., 2017). 
In my opinion, the 2017 Frascati Workshop in Mondello, namely XII Multifrequency Behaviour of High Energy Cosmic Sources, represents another confirmation of Franco Giovannelli's "Vulcano Theorem" (more details were given in Professor Franco Giovannelli's concluding talk). Apart from this theorem, the keys for a productive workshop are, in my opinion, very obvious: a nice environment, especially delicious dining, and staying together. This allows contacts and discussions among participants not only during the scientific sessions, but for the whole duration of the conference.

In comparing the previous Frascati Vulcano/Mondello workshops with the 2017 workshop, it appears to me that this was innovative in the sense that it covered a wider range of scientific fields than before, even while focusing on the multispectral astrophysics. Including a wider range of topics is definitely a positive move. For example in X-ray astronomy and astrophysics, there are communities working in various aspects, and bringing them together with the galactic and extragalactic X-ray astronomy community is surely beneficial for all. And another important factor was the growing participation of young researchers.

And what is also very important, there has been a strong participation both of leaders as well as young scientists in these fields. Most importantly, there have been many occasions for young researchers to meet famous scientists they had known previously only from the literature, both in the question periods and in informal settings.

Last but not least, I note the very high quality of the invited and review talks - this is not trivial as we face the problem of the declining quality of such talks at numerous other conferences.

In my opinion, the following selected pictures taken during the conference will better illustrate the scope, atmosphere, and success of the conference XII Multifrequency Behaviour of High Energy Cosmic Sources better than any more words.
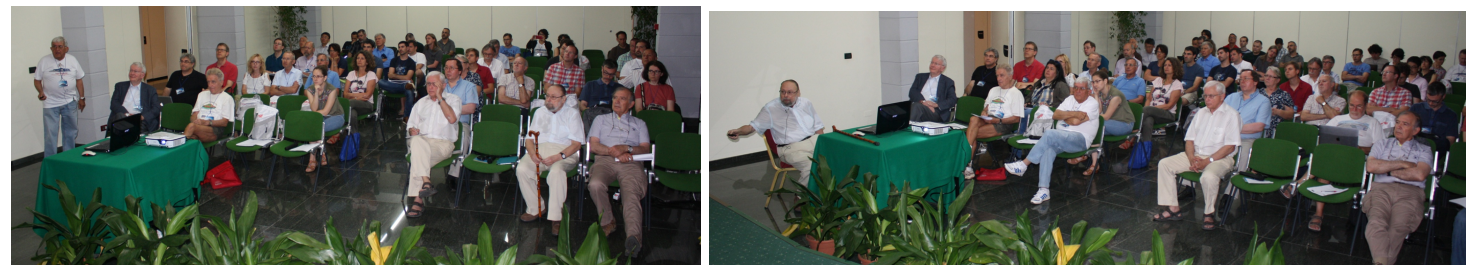

Figure 1: Scientific sessions.

\section{Conclusions}

Acknowledgments This work and the autor participation at the conference were supported by the grant GA CR 13-33324S.

\section{References}

[1] Hudec, R., Pína, L., Inneman, A., Švéda, L., LOBSTER - Astrophysics with Lobster Eye Telescopes, in Exploring the Cosmic Frontier, ESO Astrophysics Symposia European Southern Observatory 2007, pp.73-74, 2007 

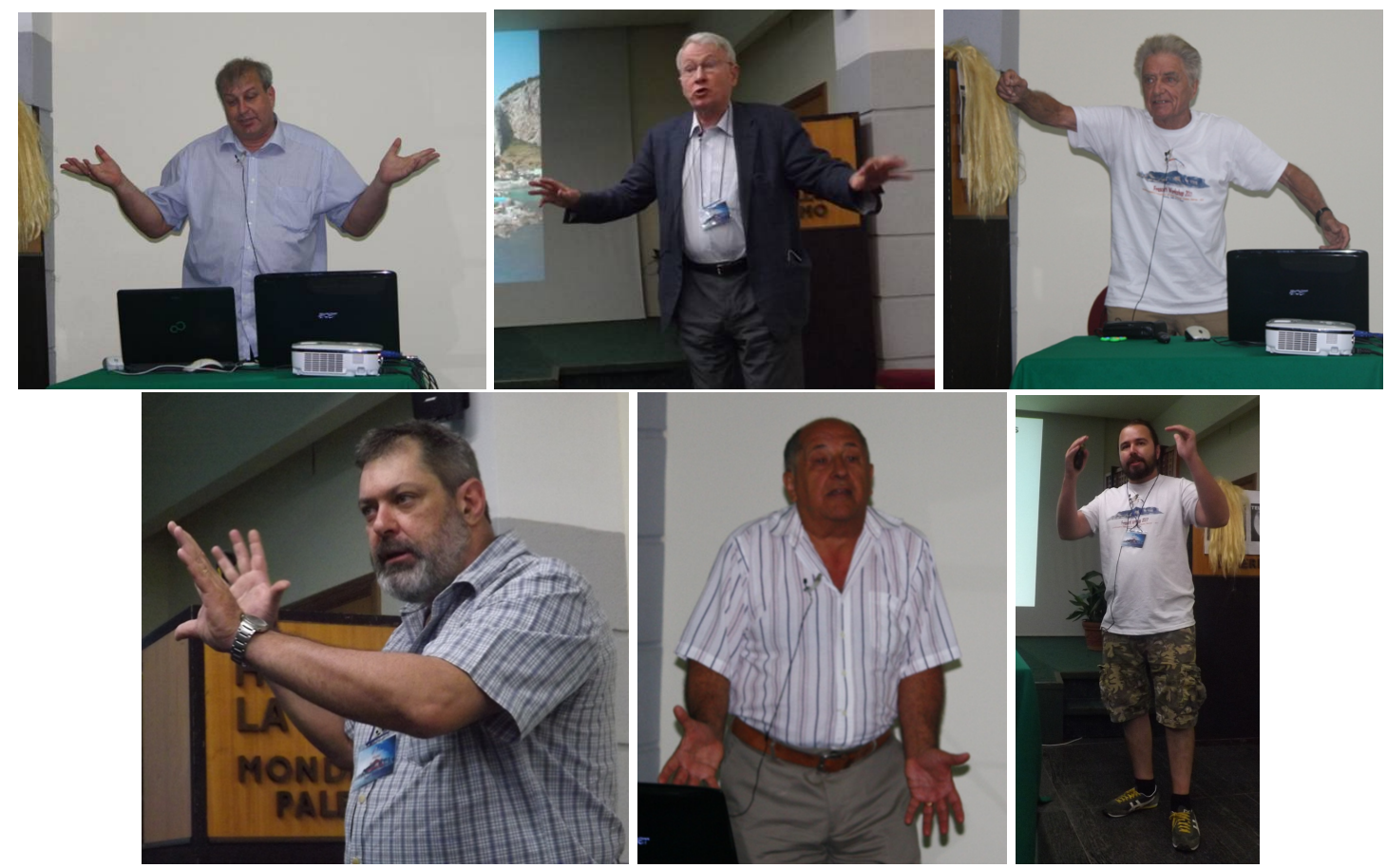

Figure 2: Speakers.
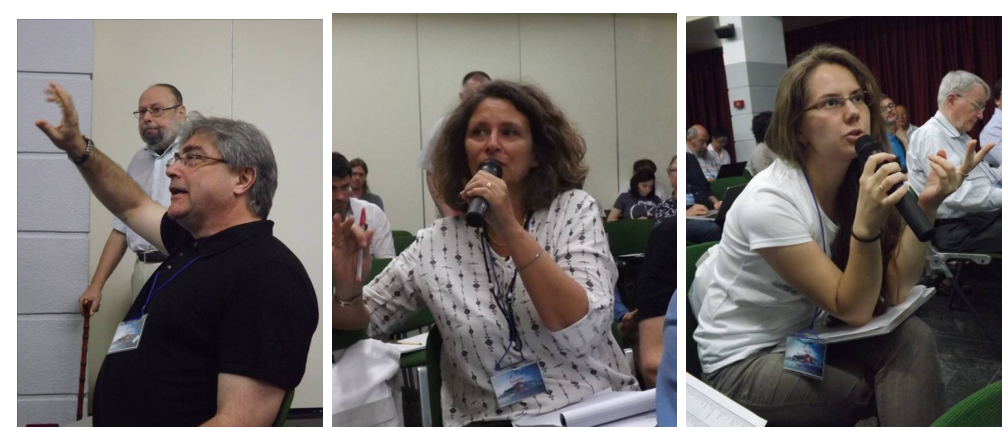

Figure 3: Sometimes live discussion after conference presentations.

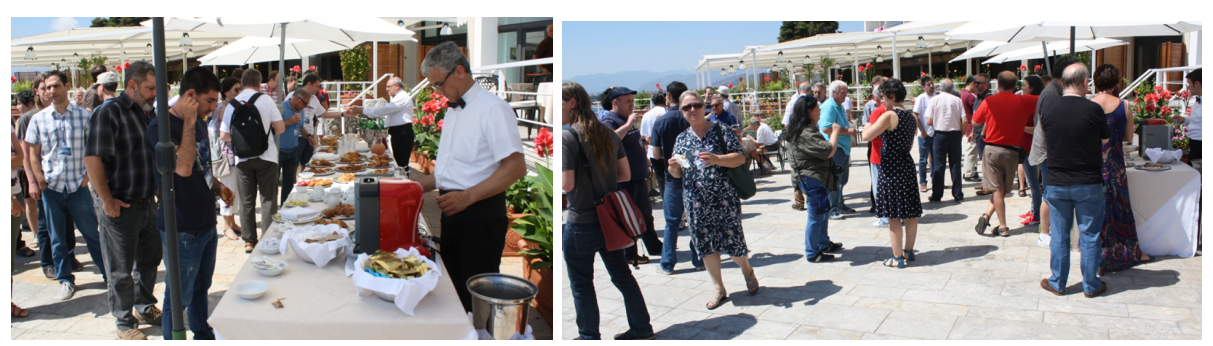

Figure 4: Coffee breaks. 

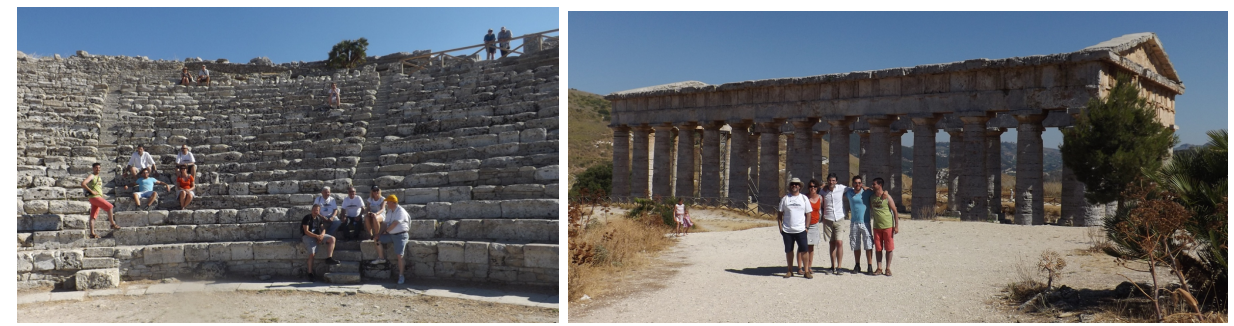

Figure 5: Conference trip to Segesta.
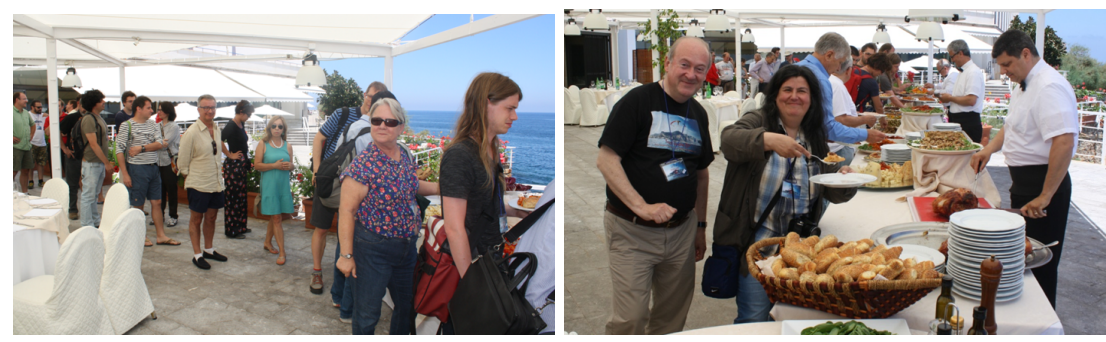

Figure 6: Dining together (lunches).
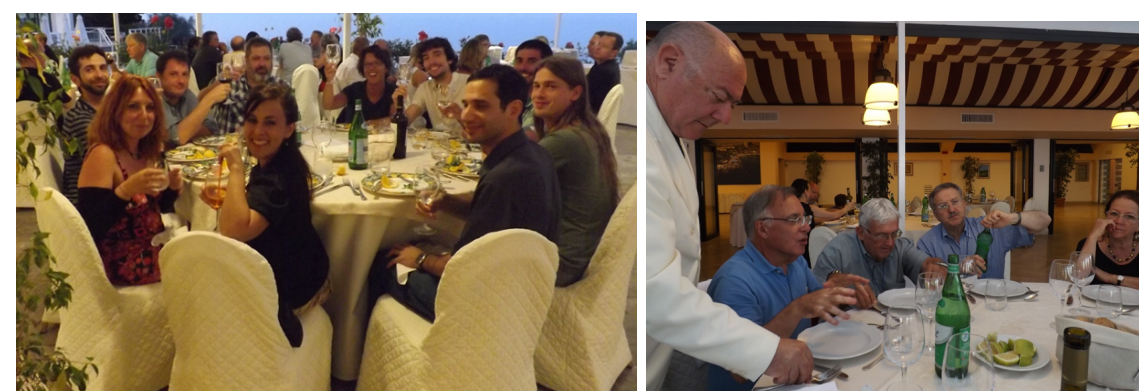

Figure 7: Dining together (dinners).
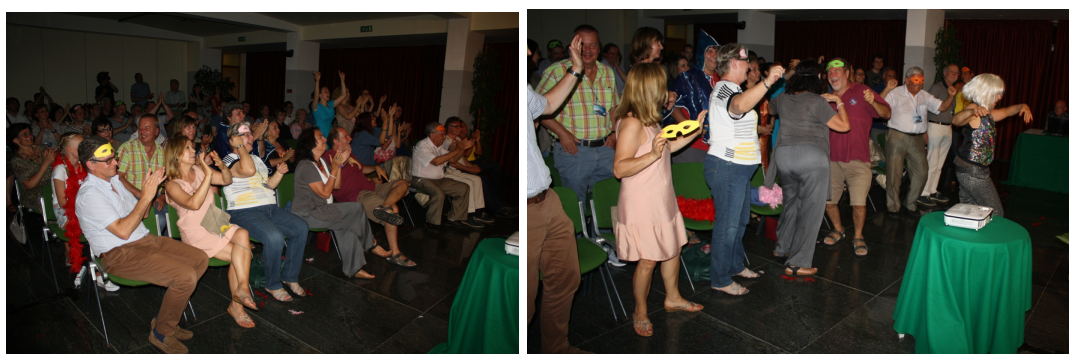

Figure 8: Conference artists performance.

[2] Urban, M., O. Nentvich, V. Stehlikova, T. Baca, V. Daniel, and R. Hudec: VZLUSAT-1: Nanosatellite with miniature lobster eye X-ray telescope and qualification of the radiation shielding composite for space application, Acta Astronautica, Volume 140, id.96 (2017) 